\title{
Traditional Birthspacing Practices and Uptake Of Family Planning During the Postpartum Period In Ouagadougou: Qualitative Results
}

\begin{abstract}
CONTEXT: In many low-income countries, postpartum women typically start contraception after the resumption of sexual intercourse or menstruation. Postpartum breast-feeding and abstinence delay these events. Information is needed on women's motivations to rely on these traditional birthspacing practices and their difficulties in starting a contraceptive method after $a$ birth in urban West Africa.
\end{abstract}

METHODS: In 2012, provider-client interactions and service delivery were observed for a week in seven health facilities in Ouagadougou, Burkina Faso, and semistructured interviews were conducted with 33 women and 12 men with infants younger than 24 months. Existing postpartum family planning services and women's transition from traditional practices to a family planning method are described.

RESULTS: Family planning is scheduled to be delivered at the six-week postpartum checkup, which women rarely attend. No women viewed amenorrhea as protective against pregnancy, and all had started or planned to start a method just before or when they resumed sexual activity. Half of the women abstained for six or more months, and some then either adopted a method they used incorrectly or did not adopt one at all. The main difficulties included providers'requirements for amenorrheic women seeking contraceptives and husbands' refusal to refrain from unprotected sex.

CONCLUSION: The initial postpartum family planning visit should occur right after delivery. Integration of family planning into immunization programs would provide opportunities to reach women who did not adopt a method early in the postpartum period. Provider barriers for amenorrheic women should be ended. Men should be involved in the postpartum family planning consultation.

International Perspectives on Sexual and Reproductive Health, 2014, 40(2):87-94; doi: 10.1363/4008714

\section{By Clémentine Rossier and Jacqueline Hellen}

Clémentine Rossier is assistant professor, Institute of Demographic and Life Course Studies (I-DEMO), University of Geneva, Switzerland, and associate researcher, Institut National d'Etudes Démographique (INED), Paris. Jacqueline Hellen is a master's student, Department of Global Health Systems and Development, School of Public Health and Tropical Medicine, Tulane University, New Orleans, LA, USA.
Research has shown that pregnancies occurring within a year of the mother's preceding birth are riskier for the health of both mother and child than those occurring later, ${ }^{1}$ and that children born within one year of a preceding birth have a higher risk of mortality than those born after longer intervals. ${ }^{2}$ To avoid the adverse outcomes associated with closely spaced births, medical guidelines recommend the uptake of a family planning method by six weeks postpartum. ${ }^{3}$ Protocols to implement these recommendations have been adopted around the world since the 1960s, and are still in place in most developing countries today. ${ }^{4}$ The standard recommendations for postpartum family planning have not changed much since then, except that in 1989 the Bellagio consensus statement added the lactational amenorrhea method* to the range of methods that can be started immediately after delivery. ${ }^{5}$

The success of postpartum family planning programs in low-income countries has been limited by poor access to prenatal care, skilled delivery and postnatal care. Indeed, access to maternal and child health services is a crucial factor in the early adoption of a family planning method after a birth. ${ }^{6}$ However, although access to maternal and child health services has increased significantly in Sub-Saharan Africa in recent decades, simultaneous progress has not been observed in contraceptive uptake in the first year after a birth, the extended postpartum period. , $^{, 7}$

One reason that health services have had limited success in the early provision of postpartum family planning in Sub-Saharan Africa is presumably women's reliance on traditional means of birthspacing. In low-income countries, women tend to adopt postpartum family planning methods only after the resumption of sexual intercourse or their menses. ${ }^{8-10}$ In Sub-Saharan Africa, both events can be substantially delayed: Women typically breast-feed their babies for up to two years, which lengthens their period of amenorrhea, and in Middle and West Africa, women abstain from intercourse for extended periods of time after a birth. ${ }^{11}$

The use of these traditional means of birthspacing is declining. In urban Africa, the somewhat lower durations of both breast-feeding and exclusive breast-feeding mean that women's menses return earlier. Durations of postpartum abstinence are also shorter in West African cities than in rural areas. ${ }^{12,13}$ Nevertheless, recent calculations show

*Women are protected from pregnancy for the first six months after a birth when they breast-feed exclusively and are amenorrheic. Women using the lactational amenorrhea method are expected to switch to another family planning method when they reach six months postpartum (or before that date, if they stop breast-feeding exclusively or start their menses). 
that the mean duration of postpartum insusceptibility to pregnancy (the period of combined amenorrhea and abstinence) lies between 15 and 20 months in most SubSaharan African countries. ${ }^{14,15}$ Because the return of menses or resumption of sexual activity still typically occurs between one and two years after the birth of a child in SubSaharan Africa, contraceptive use in the first year postpartum remains very low in the region., ${ }^{4,7}$

Existing studies, based on Demographic and Health Surveys (DHS) or similar data, show a strong link between the end of traditional means of protection and the uptake of family planning; women tend to start a modern method when they resume sex or when their period returns. ${ }^{6,9,10}$ However, these studies describe neither why African women and couples rely on traditional practices to space their births, nor why they do not adopt a contraceptive method earlier in the postpartum period. Preliminary results from a set of studies conducted in India, Ghana, Rwanda and Zambia ${ }^{16}$ found several reasons women did not start practicing contraception soon after a birth. First, many women believed, incorrectly, that they were completely protected while amenorrheic. Although amenorrhea is related to a low risk of pregnancy at the population level, the absence of menses does not guarantee protection from pregnancy for individual women (except in the restrictive time frame of the lactational amenorrhea method). Second, health care protocols usually called for family planning to be explicitly offered only once during the six-week postpartum time frame, and this single opportunity was not sufficient to reach all women. Finally, before health care providers would dispense contraceptives, they sometimes required amenorrheic women who were more than six weeks postpartum to wait for the return of their menses or to take a costly pregnancy test.

In this study, we use a qualitative approach to investigate these and other obstacles to the early uptake of family planning methods after a birth in Ouagadougou, the capital of Burkina Faso, in West Africa. According to the 2010 DHS, the median duration of breast-feeding is 20.0 months in Ouagadougou, the median duration of amenorrhea is 8.4 months and the median duration of postpartum abstinence is 6.0 months (compared with 24.0, 13.2, and 12.0 months, respectively, for the entire country). ${ }^{17}$ Altogether, women are insusceptible for a median of 11.1 months in the capital versus 15.0 months in the country as a whole. In Ouagadougou, almost all women attend prenatal visits (99\%), deliver in a health facility (97\%) and have their child vaccinated (80\% for all vaccines and $98 \%$ for the tuberculosis vaccine). Despite these contacts with the health care system, contraceptive use remains low between births: Only $27 \%$ of women have a satisfied need for family planning for spacing in Ouagadougou (11\% in Burkina Faso as a whole).

This study pays particular attention to postpartum abstinence, and to factors that may help women make a successful transition from abstinence to family planning. Considering the gender inequalities that persist in urban West
Africa's rapidly changing social context, couples may have conflicting expectations about the resumption of sexual activity, which could lead to unexpected and unprotected postpartum sexual intercourse. ${ }^{18}$ Another particular focus of this analysis is the lactational amenorrhea method, a method used by fewer than 1\% of married women in Ouagadougou, according to the 2010 DHS. Given the similarities between the protection provided by the lactational amenorrhea method and that afforded by the traditional practice of breast-feeding, this method might be able to play a larger role in providing women with contraceptive coverage in the early postpartum period. Although these practices have rarely been examined, understanding them is crucial to strengthening postpartum family planning services in Sub-Saharan Africa, an aim that is high on today's family planning agenda. ${ }^{19}$

\section{METHODS}

We collected data between April and June 2012 at seven facilities that offer family planning services in Ouagadougou, four of which are public health facilities. Of these four, two are Centres de Santé et de Promotion Sociale (known as CSPSs, roughly translating to Health and Social Advancement Centers) and two are Centres Medicaux avec Antenne Chirurgicale (CMAs, or Medical Centers with Surgical Units). The CSPSs provide primary care services, including maternal and infant health care; the CMAs are secondary level health care facilities. The three other facilities are run by nongovernmental organizations and offer low-cost reproductive health services, including family planning. Five of these seven health centers serve the population residing within the areas of the Ouagadougou Health and Demographic Surveillance system. ${ }^{20}$

An experienced Burkinabé female research assistant, contracted by the Institut Supérieur des Sciences de la Population at the University of Ouagadougou, spent one week at each facility. The assistant spent several hours each day observing provider-client interactions and the overall functioning of the various sectors of maternal and child health care services (immunization, delivery, family planning, etc.). During the observations, she occasionally asked questions of the personnel to clarify their actions. She wrote a structured observation report for each facility, which included the number of hours spent at each location, the number of staff-patient interactions observed and selected service statistics obtained from the facilities' registers. We use these observational data to describe current postpartum family planning services in Ouagadougou.

Also between April and June 2012, the same assistant invited a convenience sample of 33 females and 12 males at the facilities to participate in interviews. One-on-one interviews were preferred to focus groups to allow for indepth discussion of personal and potentially sensitive information. All discussions were conducted in Mooré (the language of the Mossi, the main ethnic group in Ouagadougou) or in French, the national language. Inclusion criteria for this study were residing in Ouagadougou and 
having given birth within the last 24 months or having a partner who had.

A semistructured questionnaire was used to collect data on attitudes toward contraception, knowledge of fertility and contraception, duration of postpartum sexual abstinence, breast-feeding practices and duration, duration of postpartum amenorrhea, attitudes on birthspacing and limiting, attitudes on postpartum abstinence, past and current contraceptive use, and preferred timing for postpartum family planning services targeted at women and men. Basic social and demographic information was also collected. Each interview lasted approximately 30 minutes. The interviews were conducted in a private area (for example, an empty room in the health facility). They were audiotaped and translated (into French, if in Mooré) during transcription by several Burkinabé research assistants with experience in transcription. Transcripts were compared with audio files to check for accuracy.

Because men rarely attend maternal health services in Burkina Faso, only eight men who were visiting the facilities were successfully recruited. Four more men were found in the vicinity (working in the parking garage of the hospital, etc.). The questionnaires for men and women were identical. However, men were unable to respond to questions on the duration of their wife's or partner's breast-feeding and amenorrhea, and could not provide information on the family planning information and services received at the different points of contact with the health system. Although the women interviewed came from diverse social backgrounds, the sample of men was more heavily weighted toward the poorly educated and those born in rural areas. Because men's and women's responses were similar on many points, the male interviews are referred to only when male knowledge and attitudes differed consistently from female responses.

The authors first analyzed the transcripts by using thematic content analysis to describe the diversity of attitudes toward contraception and practices of fertility regulation during the postpartum period. The beliefs and behaviors of each respondent were summarized in a thematic "portrait," which included key quotes. In the text, we include several exchanges between respondents and the interviewer, with "I" indicating when the interviewer was speaking and " $\mathrm{R}$ " indicating when the respondent was speaking. In the second stage, a table was compiled that included, for each female respondent, the age of her last child (9.5 months on average) and the sequence and timing (in months postpartum) of resumption of sexual intercourse, return of menses and exclusive breast-feeding. The table also contains information on whether the respondent received family planning information at the six-week checkup, at another maternal and child health appointment, or at no time after the last birth.

Seven out of 33 women were still abstaining at the time of the interview. The 26 women with a complete history of postpartum practices were included in a table (not shown) classifying the duration of their postpartum abstinence on the one hand (short-term abstinence, 1-2 months; medium-term abstinence, 3-5 months; long-term abstinence, at least six months), and on the other hand, the degree of pregnancy risk and difficulty encountered in adopting a family planning method. We classified correct use of modern methods (the lactational amenorrhea method, the Standard Days method, hormonal and surgical methods, condom) as safe, and traditional family planning method use (periodic abstinence, withdrawal) and improperly used modern methods (for example, inconsistent condom use) as entailing some risk. Women correctly using the calendar method were classified as Standard Days method users; those not using it correctly were placed in the "some risk" category if they were not using another method. Similarly, only women purposefully using the lactational amenorrhea method were classified as lactational amenorrhea method users (no cases in our sample). Difficulties in starting a family planning method were explained in the table with a brief description. Altogether, women were classified as having gone through an "easy and protected transition to family planning," a "protected but difficult transition to family planning" (both categories without a period of risk between the end of abstinence and the start of a family planning method), a "somewhat risky transition" (use of less effective methods) or a "risky transition" (no method at all used at some point).

The Institutional Review Boards of the Tulane University School of Public Health and Tropical Medicine in New Orleans, Louisiana, USA, and the National Health Ethics Committee of Burkina Faso approved the human subject protocols of this research in accordance with the Helsinki Declaration. Participants in this study signed a consent form prior to the start of their interviews. Pseudonyms were created for the analysis of the individual interviews, and no real names were retained.

\section{RESULTS}

\section{Postpartum Family Planning Services}

National health protocols call for numerous contacts with health services for pregnant women and new mothers in Burkina Faso: four prenatal visits, a skilled delivery, the six-day check-up, the six-week check-up, the weighing consultations (well-baby visits) and infant vaccination appointments. Current national guidelines stipulate that family planning be discussed and prescribed at the six-week check-up. They also mandate that health personnel provide group talks on family planning to women who are waiting to be seen for other maternal and child health visits.

Our observations confirmed that the six-week visit is indeed when family planning is discussed and prescribed on a one-on-one basis. Nurses did not routinely discuss family planning during any other scheduled visits (vaccinations, prenatal visits, etc.). During our observations, some waiting room talks took place, but they contained information only on vaccination and nutrition.

Although the six-week check-up is the visit designated for discussion of postpartum contraception, a minority of 
women actually return to health centers for this appointment. The service statistics compiled from the five centers with a maternity ward indicated, in fact, a great variation across centers, with attendance rates ranging from $4 \%$ to $33 \%$ during our observation period. The health staff acknowledged that low attendance at the six-week check-up visit is an ongoing problem. Our observations showed that women discharged after delivery did not always leave with an appointment for the six-week visit. When women were told about the appointment, it was usually advertised as a simple health check-up rather than a family planning consultation, which may contribute to the low attendance (because most women feeling healthy at that time would disregard it).

Our observations indicate that most women visited the health center at their own initiative when they needed a family planning method, often later than six weeks postpartum. They went directly to the family planning unit of the maternity center. Nurses at the family planning unit request that women past the first six weeks postpartum prove that they are not currently pregnant, either by providing the date of their last period or by undergoing a pregnancy test, which costs 1,200 West African CFA francs (US\$2.37).

\section{Abstinence and Resumption of Sex}

Even if women understand the six-week visit as a family planning visit, they presumably have little interest in getting contraceptives at that time because they rely on traditional spacing practices for several months. Data from our sample show that while about half of the women interviewed abstained for at least six months postpartum, they rarely abstained for longer than 10 months. Those who abstained six months or longer tended to have been born in rural areas and to be less educated than other women. These women displayed an attachment to cultural beliefs about postpartum sexual relations that encourage abstinence (e.g., that they would spoil the breast milk or sicken the baby if they had sex), as can be seen for example in this woman's discourse:

"If a man really wants to sleep with his wife quickly ... maybe on the day of the child's check-up, he can ask his wife to get [contraception].... [However,] certain children can't handle it; certain children vomit when women have [sexual relations]!"-Armelle, 30 years old, primary education

No respondent saw early postpartum sex as immoral or shameful in itself, but all respondents viewed closely spaced pregnancies as very harmful for the health of the baby.

A quarter of the sample abstained for just a few weeks after birth, resuming sex within two months of delivery. These women tended to be educated and born in urban areas. Given the availability of contraceptives, they did not see any value in or reason for postpartum abstinence. Rather, they felt that sex could start as soon as the woman had healed. The remainder of the women in the sample abstained for 3-5 months postpartum.
The respondents often started sexual relations before the return of menses. More than half of the sample for which we had complete information started having sexual relations before their periods came back. In contrast to the results of previous studies, no woman in our sample-regardless of her education level-reported that she thought amenorrhea alone protects against pregnancy. For example, Georgette (20 years old, with a primary education) stated: "I know the example of a girl who got pregnant just like that; she did not see her periods, but she got pregnant and even delivered." In contrast, in the sample of men, most believed women are fertile only when no longer amenorrheic. These men rarely knew when their wives' periods had resumed, however.

Only three women knew that women have a very low risk of pregnancy in the first six months of a birth if they are amenorrheic and breast-feed exclusively (lactational amenorrhea method), but none used this method. Notably, most women in the sample breast-fed exclusively for six months, and were unknowingly protected from pregnancy.

For a third of the women in the sample, the timing of the return of menses was an important factor when planning postpartum pregnancy prevention. Several waited for their periods before starting a hormonal method and then having sex. A few others used oral contraceptives to induce menstruation so that they could obtain a longer-lasting method at the clinic. Still others used condoms until their periods returned, and then switched to either a hormonal method obtained from a health center, the Standard Days method or periodic abstinence.

Overall, no woman in the sample planned to use abstinence alone to space pregnancies. And because they did not believe amenorrhea could provide complete protection, no female respondents thought they could rely on traditional practices alone (postpartum abstinence and breast-feeding-induced amenorrhea) to avoid having another baby too soon. All women in the sample had started or planned to start a family planning method around the time they resumed sex, or at some time before.

\section{Timing of Contraceptive Adoption}

The timing of the uptake of a family planning method was, in fact, tightly linked to the timing of the resumption of sexual intercourse. All of the women who started to have sex early (within 1-2 months of giving birth) also started a contraceptive method within that time period, in compliance with the national postpartum family planning protocol. Among these women, half took up a hormonal method before resuming sexual intercourse (at the six-week visit), and two used condoms when they resumed having sex. One, however, started a hormonal method only after having one unprotected sexual encounter.

Among women who abstained for between three and five months, none started a family planning method at the six-week check-up. Mamou, an exception, stated that she was given an injection without her consent (she did 
not understand what she was being given). Most mediumterm abstainers either adopted a hormonal method just before starting sex (two women) or used condoms when resuming sexual intercourse (four). Only two women in this group did not manage to adopt a family planning method at or before the resumption of sexual intercourse; both women experienced two months of pregnancy risk.

Almost all women who abstained for longer periods of time (six or more months) also waited to start a method until they were ready to have sex again. Fatimata, the one exception, adopted a method at her six-week check-up; she had had a cesarean section and her doctor recommended the implant. Five women adopted a hormonal method or an IUD before the resumption of sexual intercourse, while three used condoms, and two others practiced periodic abstinence after resuming sex. Only one woman among the long-term abstainers experienced fully unprotected intercourse; she started a hormonal method only after resuming sexual relations (but had had only one episode of unprotected intercourse).

Altogether, except for two women whose contraceptive uptake was decided by health personnel, the women interviewed reported wanting to start a family planning method before or at the resumption of sexual intercourse, and just a few failed to do so. The large variations in the duration of postpartum abstinence in this context help explain why women need to start practicing contraception at varying times in the two years after a birth.

\section{Difficulties in the Transition to Family Planning}

The most commonly used family planning methods in this sample of postpartum women were the injectable, the implant, condoms, oral contraceptive pills (to induce menstruation) and the Standard Days method (and periodic abstinence); the IUD is also used by some. Although half of the women interviewed experienced some difficulties in switching from abstinence to a family planning method, only a few were not able to overcome these difficulties and experienced periods of fully unprotected sex. A few others used less effective family planning methods and were subject to some risk.

Difficulties related to the organization of family planning services were observed in a number of cases: Some women were told to come back after their menses returned, others experienced a stock-out of their preferred method, and some could not afford the pregnancy test or the contraceptive method. Farida, a 21-year-old woman with a primary education, recounted her experience:

R: They said that [pregnancy] tests must be done before starting [family] planning.

I: So, if you haven't had your period yet, you have to take tests in order to get contraceptives?

R: Yes.

I: Why did you wait until your period returned before coming [to the health center]?

R: Because it's expensive to get a urine test.

Two other types of obstacles were widespread. First, women and men often feared the side effects of modern medical contraceptives. Many women had experienced side effects and discontinued or switched methods in the past. Kadi, a 40-year-old with a primary education who went from the pill to the IUD after her last birth, explained why she did not consider the injectable:

$\mathrm{R}$ : The first method I took was the injection in 2002; after having taken a single [three-month] shot, I could not get pregnant again. I sought some care, and it is only lately, in 2011, that I was able to give birth! So now, I say that I do not want to do injections anymore.

I: Who told you that injections can make you sterile?

$\mathrm{R}$ : That is what my husband thinks.

I: And you, do you believe it too?

R: Yes.

Such fears were just as widespread among women who switched smoothly to a family planning method as among others. Women or couples distrustful of modern medical methods turned (often with success) to condoms or the Standard Days method. Whether women and couples used these coitus-related methods correctly seemed to depend primarily on their educational level.

Another important obstacle to family planning uptake among postpartum women is their husbands. Many husbands opposed modern medical methods out of a fear of side effects. Most of these couples used condoms or a natural method, but some women who did not share their husband's fear and who had enough independent resources used a method covertly. It is important to note that the converse-husbands strongly encouraging their wives to start a method when the women were less than enthusiastic-also characterized a few cases; in these instances, the women were persuaded to use a modern method.

Women had particular difficulties in dealing with husbands who refused to abstain from sexual intercourse. Nearly all women who experienced a period of risk were contending with such a husband. Conflicts between spouses about the timing of the resumption of sexual intercourse seemed to occur regardless of the duration of postpartum abstinence. For example, when asked whether she or her husband had made the decision to resume relations, one woman said:

"It's he who imposed [sexual relations] on me. I didn't want to resume quickly like that. The Mossi say that when the child is still little ... so, I wanted to wait ... so that the child would not become ill."-Florence, 30 years old, secondary education

These women expressed concern that their desire to abstain could incite marital conflict and lead their husbands to be unfaithful. One participant noted:

"Well, I knew the resumption of sexual intercourse would happen eventually [laughs] because during our discussions, [my husband] liked to say that when the child is still small, men seek out other women, even if he assures you he will not. I told [him] that if he feels this way, I will go to get help [contraception]."-Nicole, 29 years old, primary education 
What seemed to make a difference in those situations was the women's personal or family resources. Zalissa and Salimata were able to refuse to have unprotected sex with their husbands even though it caused fights. Marie (25 years old, primary education) was unable to stand up to her husband, whether to refuse to have unprotected sex or to convince him she should start a method:

I: Have you started sexual relations with your husband?

R: Yes ... when the child was three months old.

I: Who decided to start sexual relations?

R: My husband.

I: Have you started family planning?

R: No.

I: What are you waiting for?

R: Nothing.... Often I am afraid.

I: What are you afraid of?

$\mathrm{R}$ : To do it [family planning] and to have problems with my husband.

I: What kind of problem?

R: That your husband does not agree and divorces you.

I: That is why I asked you whether you talk to him. Why are you afraid [to ask something of] your husband?

R: Because he will not accept.

Some women did not manage to keep their husbands fully at bay. Bibata's husband, for example, wanted to have sex before her stitches had healed; she told him she had to start a method before they could have sex. She called her brother-in-law, explained the situation and asked him to intervene.* Bibata finally gave in and experienced an episode of unprotected sex before getting the injectable. Olga also accepted just one unprotected sexual encounter, to avoid a fight, before starting a method.

\section{DISCUSSION}

These results are limited by the small scope of this study, conducted in a single West African city. Although some features may be unique to this context, especially those pertaining to postpartum abstinence, other results nevertheless strongly align with those of previous studies.

The results presented here show that Burkina Faso's protocol of designating the six-week follow-up visit (at the end of the postpartum period in its strict sense) as the occasion to offer family planning services is ineffective. It is difficult to motivate women to come back to health centers for family planning at a time when most of them do not yet need it. Placing a first family planning visit before women's discharge after a delivery could be much more effective in reaching all women. Such a visit may not help women adopt a method right away (because most are planning to abstain for a few months), but it would help bring information to all women and prepare them for a smooth transition to family planning at the appropriate time.

Our study confirms that a family planning appointment soon after delivery (before the woman leaves the facility or

*Traditionally, in this culture, the family is called upon to mediate marital problems, which can protect women from domineering husbands. at the six-week check-up) is necessary but not sufficient, because many women will start a method only much later after a birth. Other research conducted in Sub-Saharan Africa has pointed to the link between family planning services and immunization services as a promising avenue for offering contraceptive services throughout the extended one-year postpartum period and beyond. ${ }^{16,21}$ Our results strongly support this programmatic strategy. Our study also clarifies why so many women do not need to start a method right away: They usually abstain from sex after a birth, even if only for a few months. This is true even in East Africa, ${ }^{10}$ despite a weaker tradition of postpartum abstinence there than in Middle and West Africa. Our results suggest that abstinence in itself does not prevent women from adopting a family planning method, but that timely and personalized information on family planning could help make the transition successful.

In contrast to results from other studies, our findings indicate that women in our sample seem to know that amenorrhea alone will not protect a woman from pregnancy. In fact, our respondents seem to underestimate the power of amenorrhea combined with exclusive breast-feeding for the first six months because the lactational amenorrhea method is largely unknown, which seems to be the case in most low-income countries. ${ }^{22}$ By contrast, male respondents' positions still echo the traditional view that amenorrhea means pregnancy protection. ${ }^{23}$ This difference between the sexes suggests that women's understanding of the limits of amenorrhea is relatively new. Women's high utilization of maternal health services in Ouagadougou may explain their high level of knowledge on amenorrhea.

Our results also affirm that health services need to remove the obstacles amenorrheic women encounter when trying to obtain a family planning method. Free pregnancy tests have been shown to be a useful option, ${ }^{16}$ and a checklist of questions ${ }^{24}$ could be a cost-effective alternative. Requiring women to have their menses or to otherwise prove they are not pregnant before giving them contraceptives can lead to dangerous outcomes, such as women who do not know that combined oral contraceptives are contraindicated during breast-feeding seeking out pills on their own to induce menstruation.

With attention on the resumption of sexual activity, our analysis also suggests an important and less-explored avenue for action: involving male partners in postpartum family planning. Men rarely venture into maternal and child health centers, which are seen as female domains (exemplified by the difficulties we had in recruiting our male sample). Men are, however, likely to be present at the time of a delivery, if only to pay or to retrieve the birth certificate. A talk with a health provider at that contact could increase men's understanding of the intricacies of postpartum family planning. Providers could explain that men who refuse both abstinence and family planning put their wife and baby in danger, and that the array of methods is large enough to satisfy even those who fear side effects or have strong religious opposition to hormonal or 
barrier methods. Male involvement is usually seen as a community-outreach enterprise. ${ }^{19}$ However, interactions with providers in health facilities in the early postpartum period may be more effective, given men's lack of interest in this topic.

Finally, while we initially believed that a better promotion of the lactational amenorrhea method could strongly affect postpartum family planning, our conclusion is more modest. Given the numerous difficulties women experience in switching from abstinence to a family planning method in Ouagadougou, the protection women gained, albeit unknowingly, from the lactational amenorrhea method provided a cushion of safety for women who abstained for less than six months. None of the women in the sample who abstained for less than six months, however, would have had fewer difficulties had they been knowingly using the lactational amenorrhea method. Explicit use of the lactational amenorrhea method might have delayed their confrontation of their obstacles to contraception (husbands, lack of funds, side effects of methods, the necessity to have their periods, etc.), but would not have eliminated their difficulties. They would probably have started their method later, still with glitches, but without a safety net.

\section{Conclusion}

These results show that the traditional and the modern coexist and often conflict in postpartum pregnancy prevention in urban West Africa. The transition from traditional birthspacing practices to modern family planning is accompanied by some (often brief) episodes of risk-taking, because neither individuals nor health systems are equipped to deal with the complex evolution of reproductive norms. Traditional practices of fertility regulation are insufficient to space births in Ouagadougou today, yet current family planning services have not managed to cover the reproductive needs of couples during the postpartum period. Better integration of family planning counseling and provision during existing points of contact is required to ensure a higher quality of comprehensive reproductive health care in this context. Men's involvement in postpartum family planning counseling sessions could also help. The authority of health staff could help move men toward a greater understanding of the challenges involved in abandoning postpartum abstinence, and would give women support in their struggle for protected intercourse after a birth.

\section{REFERENCES}

1. DaVanzo J et al., Effects of interpregnancy interval and outcome of the preceding pregnancy on pregnancy outcomes in Matlab, Bangladesh, British Journal of Obstetrics and Gynaecology, 2007, 114(9):1079-1087

2. Rutstein SO, Further evidence of the effects of preceding birth intervals on neonatal, infant and under-five-years mortality and nutritional status in developing countries: evidence from the Demographic and Health Surveys, DHS Working Papers, Calverton, MD, USA: Macro International, 2008, No. 41.

3. World Health Organization (WHO), Programming Strategies for Postpartum Family Planning, Geneva: WHO, 2013.

4. Ross JA and Winfrey WL, Contraceptive use, intention to use and unmet need during the extended postpartum period, International Family Planning Perspectives, 2001, 27(1):20-27.

5. Kennedy KI, Rivera R and McNeilly AS, Consensus statement on the use of breastfeeding as a family planning method, Contraception, 1989, 39(5):477-496

6. Borda M and Winfrey W, Postpartum Fertility and Contraception: An Analysis of Findings from 17 Countries, Baltimore, MD, USA: Jhpiego, 2010.

7. Adeyemi $\mathrm{AB}$ et al., The unmet need for contraception among Nigerian women in the first year post-partum, European Journal of Contraception \& Reproductive Health Care, 2005, 10(4):229-234.

8. Becker S and Ahmed S, Dynamics of contraceptive use and breastfeeding during the postpartum period in Peru and Indonesia, Population Studies, 2001, 55(2):165-179.

9. Gebreselassie T, Rutstein SO and Mishra V, Contraceptive use, breastfeeding, amenorrhea and abstinence during the postpartum period: an analysis of four countries, DHS Analytical Studies, Calverton, MD, USA: Macro International, 2008, No. 14

10. Ndugwa RP et al., Menstrual pattern, sexual behaviors and contraceptive use among postpartum women in Nairobi urban slums, Journal of Urban Health, 2011, 88(Suppl. 2):S341-S355.

11. Page $\mathrm{H}$ and Lesthaeghe $\mathrm{R}$, Child-Spacing in Tropical Africa: Traditions and Change, London: Academic Press, 1981.

12. Benefo KD, The determinants of the duration of postpartum sexual abstinence in West Africa: a multilevel analysis, Demography, 1995, 32(2):139-157.

13. Desgrées-du-Loû A and Brou H, Resumption of sexual relations following childbirth: norms, practices and reproductive health issues in Abidjan, Côte d'Ivoire, Reproductive Health Matters, 2005 , 13(25):155-163.

14. Brown M, When ancient meets modern: the relationship between postpartum non-susceptibility and contraception in Sub-Saharan Africa, Journal of Biosocial Science, 2007, 39(4):493-515.

15. Supriya M and Guengant J-P, An analysis of the proximate determinants of fertility in Sub-Saharan Africa, paper presented at the International Conference on Family Planning, Addis Ababa, Ethiopia, Nov.12-15, 2013.

16. FHI 360, Postpartum Family Planning: New Research Findings and Program Implications, 2012, <http://www.fhi360.org/sites/default/ files/media/documents/Postpartum\%20Family\%20Planning.pdf>, accessed Feb. 14, 2014.

17. Institut National de la Statistique et de la Démographie (INSD) and ICF International, Enquête Démographique et de Santé et à Indicateurs Multiples du Burkina Faso 2010, Calverton, MD, USA: INSD and ICF International, 2012.

18. Bajos $\mathrm{N}$ et al., Normative tensions and women's contraceptive attitudes and practices in four African countries, Population, 2013, 68(1):15-36.

19. WHO et al., Statement for Collective Action for Postpartum Family Planning, 2013, <http://www.who.int/reproductivehealth/topics/ family_planning/Statement_Collective_Action.pdf?ua=l>, accessed Feb. 14, 2014

20. Rossier C et al., Profile: the Ouagadougou Health and Demographic Surveillance System, International Journal of Epidemiology, 2012, 41(3):658-666.

21. Huntington D and Aplogan A, The integration of family planning and childhood immunization services in Togo, Studies in Family Planning, 1994, 25(3):176-183.

22. Short Fabic M and Choi Y, Measuring use of the lactational amenorrhea method through the Demographic and Health Surveys: data quality and implications, paper presented at the annual meeting of the Population Association of America, New Orleans, April 11-13, 2013.

23. Dehne KL, Knowledge of, attitudes towards and practices relating to child-spacing methods in northern Burkina Faso, Journal of Health, Population, and Nutrition, 2003, 21(1):55-66.

24. Daniele M, London School of Tropical Hygiene and Medicine, London, personal communication, Jan. 10, 2014. 


\section{RESUMEN}

Contexto: En numerosos países de bajos ingresos, las mujeres en período postparto típicamente comienzan a usar anticoncepción después de reanudar las relaciones sexuales o la menstruación. La lactancia postparto y la abstinencia retrasan estos eventos. Se necesita información sobre aquello que motiva a las mujeres de residencia urbana en África Occidental a depender de estas prácticas tradicionales de espaciamiento de hijos, así como sobre las dificultades que enfrentan para comenzar a usar un método anticonceptivo después del parto.

Métodos: En 2012, se observaron las interacciones entre usuarias y proveedores, así como la prestación de servicios en siete instituciones de salud en Ouagadougou, Burkina Faso a lo largo de una semana, y se realizaron entrevistas semiestructuradas a 33 mujeres y 12 hombres con infantes menores de 24 meses. Se describen los servicios existentes de planificación familiar postparto y la transición a partir de prácticas tradicionales a un método de planificación familiar de las mujeres. Resultados: La planificación familiar está programada para ser otorgada en el chequeo a las seis semanas postparto, al cual rara vez acuden las mujeres. Ninguna de las mujeres consideró la amenorrea como un medio de protección contra el embarazo, y todas habian comenzado o planeado iniciar el uso de un método justo antes o cuando reanudaran su actividad sexual. La mitad de las mujeres se abstuvo por seis o más meses, y luego, algunas adoptaron un método que usaron de manera incorrecta o no adoptaron ningún método. Las principales dificultades incluyeron los requerimientos de los proveedores para las mujeres amenorréicas que deseaban anticonceptivos y el rechazo de los maridos de abstenerse de tener relaciones sexuales sin protección.

Conclusión: La visita inicial de planificación familiar postparto debe ocurrir inmediatamente después del parto. La integración de la planificación familiar a los programas de inmunización ofrecería oportunidades para llegar a las mujeres que no adoptaron un método al principio del período postparto. Debería ponerse fin a las barreras impuestas por los proveedores a las mujeres amenorréicas. Los hombres deberían involucrarse en las consultas de planificación familiar postparto.

\section{RÉSUMÉ}

Contexte: Dans de nombreux pays à faibles revenus, les femmes post-partum adoptent généralement la contraception après la reprise des rapports sexuels ou de la menstruation.
L'allaitement et l'abstinence post-partum diffèrent ces événements. Il serait utile de documenter la motivation des femmes à compter sur ces pratiques traditionnelles d'espacement des naissances et leurs difficultés à adopter une méthode contraceptive après une naissance en Afrique occidentale urbaine.

Méthodes: En 2012, les échanges entre prestataires et clientes et les prestations de services ont été observés pendant une semaine dans sept structures de santé de Ouagadougou (Burkina Faso) et des entretiens semi-structurés ont été menés avec 33 femmes et 12 hommes parents d'enfants de moins de 24 mois. Les services de planification familiale post-partum existants et la transition des femmes des pratiques traditionnelles à une méthode de planification sont décrites.

Résultats: La planification familiale est au programme de la consultation post-partum prévue six semaines après l'accouchement, à laquelle peu de femmes assistent cependant. Aucune femme ne considérait l'aménorrhée comme une protection contre la grossesse et toutes avaient adopté une méthode ou en planifiaient l'adoption juste avant la reprise de l'activité sexuelle ou au moment de celle-ci. La moitié des femmes avaient pratiqué l'abstinence pendant au moins six mois et certaines avaient ensuite adopté une méthode qu'elles pratiquaient incorrectement ou n'en avaient adopté aucune. Les principales difficultés tenaient aux exigences des prestataires concernant les femmes aménorrhéiques désireuses de contraception et au refus des maris d'éviter les rapports non protégés. Conclusion: La visite initiale de planification familiale postpartum devrait avoir lieu juste après l'accouchement. L'intégration de la planification familiale dans les programmes de vaccination donnerait l'occasion d'atteindre les femmes qui n'ont pas adopté de méthode en début de période postpartum. Les obstacles opposés par les prestataires aux femmes aménorrhéiques doivent être levés. Il serait utile que les hommes participent à la consultation de planification familiale post-partum.

\section{Acknowledgments}

The authors acknowledge Jocelyne Kyelem, their research assistant, and thank Leigh Senderowicz for her comments and editing. Jane Bertrand of Tulane University School of Public Health and Tropical Medicine and the Bill and Melinda Gates Foundation (grant OPP1017071) provided them with the opportunity to study postpartum family planning in Ouagadougou, and the Swiss National Science Foundation (PPOOP1_144717/1) afforded them time to write.

Author contact: Clementine.rossier@unige.ch 